\title{
Design of clamping-pot-type planetary gear train transplanting mechanism for rice wide-narrow-row planting
}

\author{
Lei Wang ${ }^{1}$, Liang Sun ${ }^{1,2 *}$, Hengmin Huang ${ }^{1}$, Yaxin $\mathrm{Yu}^{1,2}$, Gaohong $\mathrm{Yu}^{1,2}$ \\ (1. Faculty of Mechanical Engineering \& Automation, Zhejiang Sci-Tech University, Hangzhou 310018, China; \\ 2. Zhejiang Province Key Laboratory of Transplanting Equipment and Technology, Hangzhou 310018, China)
}

\begin{abstract}
To design a clamping-pot-type wide-narrow-row pot seedling transplanting (WPST) mechanism with desired spatial beak-shaped trajectory and working posture, a new design method of planetary gear train transplanting mechanism (PGTM) with non-circular gears based on several key spatial poses (position and posture) was proposed. The PGTM was simplified to a spatial open-loop chain with two-revolute (2R) joints. The geometric constraint equations containing only the structural parameters of the chain were then established on the basis of the three key spatial poses, and the homotopy algorithm was used to obtain all the required parameters of the mechanism. In accordance with the parameters obtained, the relative angular displacement relation between the planet carrier and the transplanting arm was optimized, the trajectory of the mechanism was replayed, and the total transmission ratio was determined. The degree of freedom of the spatial $2 \mathrm{R}$ mechanism was reduced by attaching to the unequal gear pair, and the transmission ratio was distributed in accordance with the gear type to realize the design of a non-circular gear pitch curve. Lastly, a clamping-pot-type PGTM for rice WPST driven by the combination of planar non-circular and non-conical gears was designed, and virtual simulation and prototype test were conducted. Results showed that the simulation and prototype test trajectories were consistent with the desired trajectory. Under the operating speeds of $50 \mathrm{r} / \mathrm{min}$ and $90 \mathrm{r} / \mathrm{min}$, the success rates of seedling picking were $95.32 \%$ and $90.15 \%$, respectively, which verified the feasibility of the theoretical method. This method could provide a reference for the design of a spatial PGTM with nonuniform transmission.
\end{abstract}

Keywords: rice pot seedling, wide-narrow-row transplanting, spatial trajectory, planetary gear train, non-circular gear DOI: $10.25165 /$ j.ijabe.20211402.5975

Citation: Wang L, Sun L, Huang H M, Yu Y X, Yu G H. Design of clamping-pot-type planetary gear train transplanting mechanism for rice wide-narrow-row planting. Int J Agric \& Biol Eng, 2021; 14(2): 62-71.

\section{Introduction}

Wide-narrow-row pot seedling transplanting (WPST) of rice is a combination of transplanting of rice pot seedlings and wide-narrow-row planting, which utilizes the advantages, such as avoiding damage to seedlings, rapid green, adequate ventilation, and disease prevention, and can effectively improve the yield and quality of rice ${ }^{[1,2]}$. At present, the transplanting of rice pot seedlings can be divided into ejection-type swinging and clamping-type transplanting in accordance with the different ways of picking seedlings ${ }^{[3]}$. Clamping-type transplanting can be divided into clamping-seedling and clamping-pot types on the basis of the difference in clamped seedling parts (stem or soil pot). Japan's ejection transplanter has a complex structure, which requires multiple sets of mechanisms to complete transplanting and is expensive; it is unsuitable for China's national conditions ${ }^{[4]}$. The clamping-type planetary gear train transplanting mechanism (PGTM) can complete the operations of clamping, extracting,

\section{Received date: $2020-06-22 \quad$ Accepted date: 2020-12-01}

Biographies: Lei Wang, PhD candidate, research interests: design and optimization of agricultural machinery, Email: 714523895@qq.com; Hengmin Huang, MS, research interests: design and optimization of agricultural machinery, Email: 1468018219@qq.com; Yaxin Yu, PhD, Associate Professor, research interests: design and optimization of agricultural machinery, Email: yyxin@zstu.edu.cn; Gaohong Yu, PhD, Professor, research interests: design and optimization of agricultural machinery, Email: yugh@zstu.edu.cn.

*Corresponding author: Liang Sun, PhD, Associate Professor, research interests: design and optimization of agricultural machinery. Faculty of Mechanical Engineering \& Automation, Zhejiang Sci-Tech University, Hangzhou 310018, China. Tel: +86-571-86843756, Email: liangsun@ zstu.edu.cn. transporting, and pushing seedlings by using a single mechanism. It has a compact structure, continuous and stable work, and low cost and has become an important direction for the research of various transplanting machines ${ }^{[5,6]}$.

Konishi et al. ${ }^{[7]}$ used the characteristics of the variable transmission ratio of an eccentric gear pair to apply the PGTM of eccentric gear to the transplanting of rice blanket seedlings. Zhou et al. ${ }^{[8]}$ proposed a Bezier gear PGTM and obtained the planar "8"-shaped trajectory required for transplanting rice seedlings in clamping-seedling type. Ye et al. ${ }^{[9,10]}$ combined incomplete and non-circular gear mechanisms to obtain the characteristics of a large transmission ratio needed to realize a specific transplanting trajectory shape. They also designed a clamping-seedling-type rice pot seedling transplanting mechanism with equal row spacing through the optimization of mechanism parameters. Sun et al. ${ }^{[11]}$ designed a non-conical PGTM by optimizing and adjusting the mechanism parameters and obtained a spatial " 8 "-shaped transplanting trajectory suitable for WPST. However, guaranteeing the consistency of clamped seedling parts by using the clamping-seedling-type transplanting mechanism is difficult in consideration of the difference in rice seedling growth. Especially when the clay sticks on the seedling paws, the success rate of picking seedlings is easy to reduce, and the pushing paw cannot be pushed completely into the soil pot of seedlings; consequently, the planting effect cannot be effectively controlled. Yu et al. ${ }^{[12]}$ designed a clamping-pot-type rice pot seedling transplanting mechanism by optimizing the parameters of non-circular and incomplete non-circular gear mechanisms that can directly insert the seedling needle into the pot to take out the seedlings, and the 
soil pot will be pushed away from the seedling needle under the action of pushing seedling paw. Accordingly, the seedlings will have a good vertical degree of planting, but this mechanism is only suitable for transplanting in equal rows. Moreover, the design of the abovementioned mechanisms is to determine the specific structure of the transplanting mechanism and obtain the trajectory that meets the requirements of transplanting by adjusting the mechanism parameters. Nevertheless, the reasonable parameters are obtained via the main trial-and-error approximation due to the multiple parameters and strong coupling. As a result, the motion flexibility (variable transmission ratio characteristics) of unequal speed transmission is inadequately reflected.

Guo et al. ${ }^{[13]}$ analyzed the transmission ratio and transplanting trajectory shape of a PGTM with eccentric gear in detail. Bae ${ }^{[14]}$ studied the transplanting mechanism of rice blanket seedlings by first planning the transplanting trajectory and then using the trajectory inverse to calculate the corresponding parameters of PGTM. Zhao et al. ${ }^{[15]}$ established an inverse kinematic model of a mechanism based on the transplanting static trajectory, solved the nonuniform transmission ratio function, and designed a non-circular gear pitch curve. Sun et al. ${ }^{[16]}$ reversely designed a wide-narrow distance transplanting mechanism with non-conical gear train wide by using a spherical trajectory. The reverse design of the mechanism by using the transplanting trajectory can make the trajectory formed by the mechanism close to the agronomic requirements of transplanting, and the target is vital. However, in the aforementioned design, the transmission ratio is solved when the parameters of other mechanisms are determined, and the posture factor of the transplanting arm is not considered in the trajectory planning. Sun et al. ${ }^{[17,18]}$ considered the posture of the transplanting arm when designing the transplanting of rice seedlings in reverse, but the trajectories realized using the mechanism are simple plane trajectories and cannot be used for the spatial trajectories required for WPST. When using the D-H matrix transformation to establish a reverse model of the spatial PGTM, a tedious problem in solving the higher-order polynomial equation occurs $^{[19]}$.

Therefore, this study presents a design method for a PGTM with unequal velocity gear based on several critical spatial poses (position and posture) of a spatial beak-shaped trajectory. The constraint equations of the simplified PGTM (spatial open-loop chain with two-revolute [2R] joints) are established in accordance with the spatial geometric constraint relationship. The equations established using this method contain only the structural parameters of the mechanism and are geometrically intuitive. The homotopy algorithm does not need the initial value and can rapidly solve all the mechanism parameters that meet the design requirements. The blindness of the initial parameter selection of the mechanism was avoided. Lastly, a clamping-pot-type PGTM of rice WPST driven by the combination of planar non-circular and non-conical gears was designed, and the feasibility of the theoretical method was verified through simulation and seedling test.

\section{Transplanting trajectory requirements}

WPST is a planting pattern to plant rice seedlings in wide rows and narrow rows at the same planting density. In China, WPST of rice is mostly planted with a wide-row distance of $400 \mathrm{~mm}$ and a narrow-row distance of $200 \mathrm{~mm}^{[11,19]}$. As shown in Figure 1, the distance between adjacent seedling picking positions on the seedling box is $300 \mathrm{~mm}$. In order to achieve WPST, a spatial trajectory is required to realize the lateral offset of $50 \mathrm{~mm}$ between the picking seedling point and the pushing seedling point. And considering the advantages of the clamping-pot-type transplanting, a spatial beak-shaped trajectory shown in Figure 2 is proposed to realize the clamping-pot-type WPST of rice.

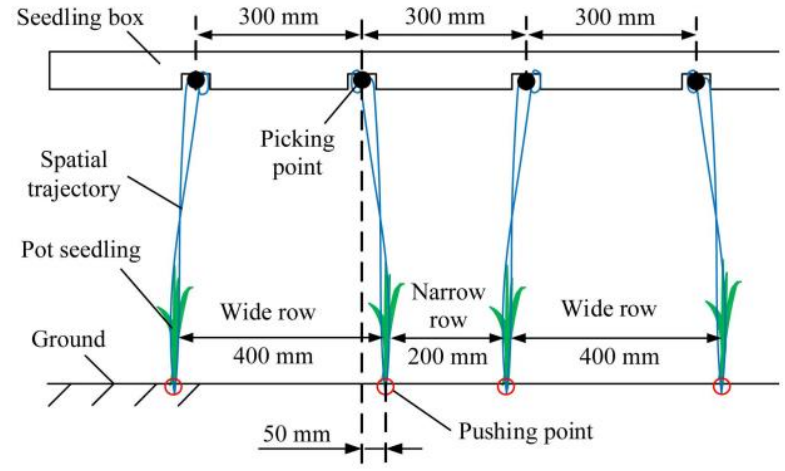

Figure 1 Schematic diagram of WPST

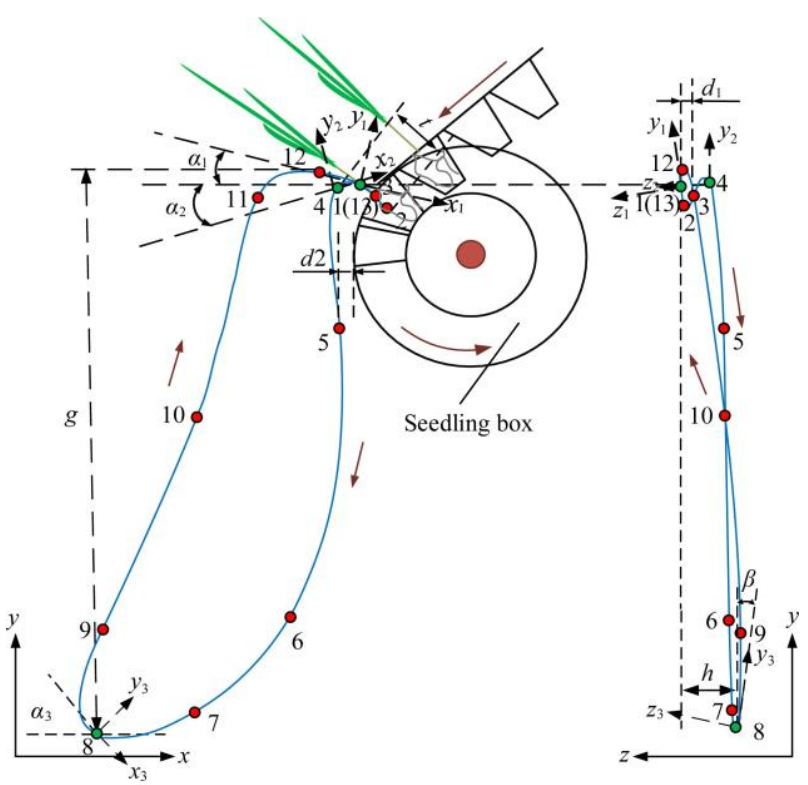

Figure 2 Spatial beak-shaped trajectory

The clamping-pot-type WPST mainly includes four actions: clamping, extracting, transporting, and pushing seedlings. For improving the success rate of picking seedlings, the $z$-direction offset of the seedling paw of the transplanting mechanism should be as small as possible when seedling clamping. That is, the $z$-direction displacement of the trajectory curve between points 1 (starting point of clamping seedlings) and 2 (clamping point of the pot) should be less than $3 \mathrm{~mm}$. Point 4 is the endpoint of extracting seedlings, points 1-4 indicate the process of picking seedlings. When the transplanting mechanism picks seedlings, the seedling paw enters the soil pot from point 1 , clamp the pot at point 2 , and then pull the seedlings out to point 4 . To realize the clamping-pot-type transplanting, points $2-4$ are designed as an approximately straight line, which is convenient for the seedling paw to enter the pot to remove the seedlings. The straight-line distance between points 2 and 4 is required to be greater than the depth of the pot tray of $20 \mathrm{~mm}$ to remove seedlings from the pot tray completely. The trajectory of points $4-8$ is the seedlingtransporting process. The distance $d_{2}$ between the transplanting trajectory and seedling box should be greater than the height of a soil pot, and the seedlings should be pushed into the soil rapidly at point 8. To achieve wide-narrow-row planting, a $z$-direction displacement of $50 \mathrm{~mm}$ (suitable for planting with a wide-row distance of $400 \mathrm{~mm}$ and a narrow-row distance of $200 \mathrm{~mm}$ ) is 
required between points 1 and 8 . The trajectory segment from points $9-13$ is an empty return process to prepare for the next seedling picking action.

From the agronomic requirements of clamping-pot-type WPST, the transplanting mechanism should meet the following requirements:

1) The transplanting arms should not interfere with each other during the mechanism movement;

2) The clamping angle $\alpha_{1}$ (the angle between the seedling paw and the $x$-axis at point 1 ) should be between $-5^{\circ}$ and $15^{\circ}$;

3) The lateral displacement $d_{1}$ of the trajectory of clamping seedlings should be less than $3 \mathrm{~mm}$ to improve the success rate;

4) The length of the trajectory of the seedling-extracting section $t \geq 25 \mathrm{~mm}$;

5) The distance between the trajectory of the seedlingtransporting section and seedling box is $d_{2}>20 \mathrm{~mm}$, and the gap should be sufficient to prevent the collision between the soil pot and pot tray;

6) The pushing angle $\alpha_{3}$ (the angle between the seedling paw and the $x$-axis at point 8 ) should be between $45^{\circ}$ and $65^{\circ}$, and the lateral angle of seedling paw $\beta<20$; hence, the angle between the pot seedling and ground is not less than $70^{\circ}$;

7) The total lateral displacement of the tips of the transplanting arms from points $1-8$ is $h=50 \mathrm{~mm}$;

8) The transplanting trajectory height $g>250 \mathrm{~mm}$.

On the basis of the abovementioned transplanting requirements, the posture of transplanting arms at the positions of clamping, extracting, and pushing seedlings is related to the quality of rice pot seedlings. The three points correspond to points 1 (starting point of clamping seedlings), 4 (end point of extracting seedlings), and 8 (point of pushing seedlings) in Figure 2. In accordance with the reference system shown in Figure 2 , the $4 \times 4$ homogeneous matrix can be used to describe the positions and postures of the three points. In this study, the parameters of the transplanting mechanism of clamping-pot-type WPST were solved through the given three spatial poses.

\section{Spatial geometric constraint equations of mechanism}

In order to realize the spatial trajectory required for the WPST, the spatial PGTM configuration shown in Figure 3 is adopted in this study. The transmission part of the mechanism is composed of seven non-circular gears (plane or spatial). The positional relationship of the input and output axes is staggered or intersected. The mechanism is symmetrical, and the working principle is explained by taking the gear transmission on one side as an example: the sun gear 2 is installed on the framework, and the intermediate gear 3 meshing with the sun gear 2 is fixed on the intermediate axis together with the intermediate gear 4 . The planetary gear 5 and the intermediate gear 4 mesh with each other. One end of the output axis extends out of gear box 1 (planet carrier), and is fixedly connected with the transplanting arm 6 . When the mechanism is working, the power is input by the input axis, which drives the planet carrier 1 fixedly connected with the input axis, and the planet carrier 1 rotates clockwise. Through non-circular gear transmission, the movement of the output axis is a combination of counterclockwise rotation relative to the planet carrier 1 and clockwise rotation with the input axis. In addition, the position relation between input and output axes is staggered or intersected, which makes the transplanting arm swing nonuniformly and periodically in space, forming the spatial trajectory required by WPST.
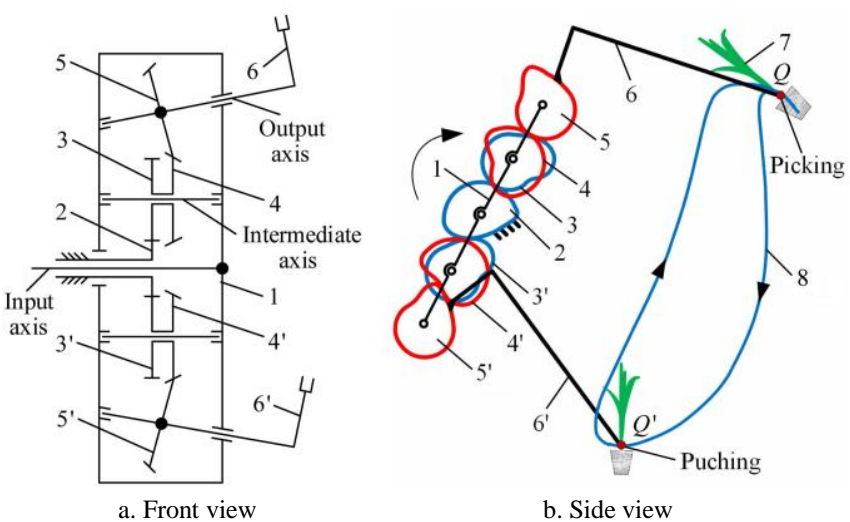

1. Gear box (Planet carrier) 2. Sun gear 3(3'). Intermediate gear I 4(4'). Intermediate gear II 5(5'). Planetary gear 6(6'). Transplanting arm 7. Pot seedling 8 . Transplanting trajectory

Figure 3 Schematic diagram of PGTM

The motion trajectory of PGTM is formed using point $Q$ of the transplanting arm, and the absolute motion of the connection between the center of the planetary gear and point $Q$ is reciprocating swing, that is, the absolute angular displacement of the transplanting arm is a periodic function of a certain small angle. If the transmission performance of the gears in PGTM is disregarded, this type of PGTM can be simplified as a spatial $2 \mathrm{R}$ mechanism.

In Figure $4, L_{1}$ represents the length of the planetary carrier of PGTM, that is, the distance from the center of the sun gear to the center of the planet gear. $L_{2}$ represents the distance from the axis of the planet gear to the tip $Q$ of the transplanting arm. $F=(\mathbf{F}, \mathbf{B} \times$ $\mathbf{F})$ and $W_{j}=\left(\mathbf{W}_{j}, \mathbf{P}_{j} \times \mathbf{W}_{j}\right)$ represent the input and output axes of the mechanism, respectively, where $\mathbf{F}$ is the $3 \times 1$ unit direction vector of the input axis, $\mathbf{B}$ is the position vector of a point on the input axis, $\mathbf{W}_{j}$ is the $3 \times 1$ unit direction vector of the output axis, and $\mathbf{P}_{j}$ is the position vector of a point on the output axis. Points $\mathbf{B}$ and $\mathbf{P}_{j}$ are the intersection points of the common perpendicular on the input and output axes, respectively. The angle between the input and output axes is $\alpha$. When the mechanism moves, link $L_{1}$ rotates around input axis $F$, while link $L_{2}$ rotates around output axis $W$ relative to $L_{1}$. Under the joint action of the input and output axes, the end point $Q$ of the mechanism forms trajectory $C$. Therefore, the design of a spatial $2 \mathrm{R}$ mechanism first needs to determine its structural parameters, that is, determine the direction vectors $\mathbf{F}, \mathbf{W}_{j}$ of the two axes and the coordinates of points $\mathbf{B}$ and $\mathbf{P}_{j}$.

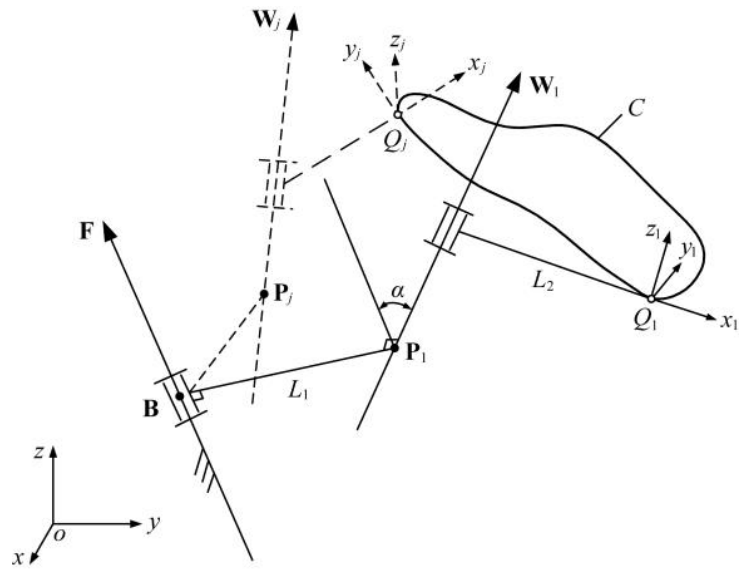

Figure 4 Spatial 2R mechanism

The changes in the motion and function of the spatial mechanism generally depend on the constraints imposed by each link of the kinematic chain ${ }^{[20]}$. In accordance with the spatial 
motion relationship of the spatial $2 \mathrm{R}$ mechanism, the geometric constraint equations are established and solved, and the mechanism parameters that meet the design requirements can be obtained.

As shown in Figure 4, $Q_{1}$ and $Q_{j}$ are two points on trajectory $C$, and their poses are described as $\left[\mathbf{T}_{1}\right],\left[\mathbf{T}_{j}\right]$. The rigid body displacement matrix from $Q_{1}$ movement to $Q_{j}$ can be expressed as

$$
\left[\mathbf{T}_{1 j}\right]=\left[\mathbf{T}_{j}\right]\left[\mathbf{T}_{1}\right]^{-1}=\left[\begin{array}{cc}
\mathbf{R}_{1 j} & \mathbf{d}_{1 j} \\
0 & 1
\end{array}\right], j=2,3, \ldots, n
$$

where, $\mathbf{R}_{1 j}$ are $3 \times 3$ rotation matrix and $\mathbf{d}_{1 j}$ are $3 \times 1$ translation vector.

Let point $\mathbf{P}_{1}$ be the point where the rotating pair on the output axis is located, and the motion relationship between $\mathbf{P}_{1}$ and $\mathbf{P}_{j}, \mathbf{W}_{1}$ and $\mathbf{W}_{j}$ can be obtained from Equations (1).

$$
\begin{aligned}
{\left[\mathbf{P}_{j}\right] } & =\left[T_{1 j}\right]\left[\mathbf{P}_{1}\right] \\
{\left[\mathbf{W}_{j}\right] } & =\left[R_{1 j}\right]\left[\mathbf{W}_{1}\right]
\end{aligned}, j=2,3, \ldots, n
$$

Points $\mathbf{B}$ and $\mathbf{P}_{j}$ are the intersection points of the common perpendicular on the input and output axes, respectively, and the distance remains unchanged.

$$
\left[\mathbf{P}_{1}-\mathbf{B}\right]^{\mathrm{T}}\left[\mathbf{P}_{1}-\mathbf{B}\right]=\left[\mathbf{P}_{j}-\mathbf{B}\right]^{\mathrm{T}}\left[\mathbf{P}_{j}-\mathbf{B}\right], j=2,3, \ldots, n
$$

The straight lines $\mathbf{B} \mathbf{P}_{j}$ are connected with and rotate around the $F$-axis and $W$-axis by rotating pairs; therefore, the motion plane of $\mathbf{B P}_{j}$ should be perpendicular to the $F$-axis and $W$-axis.

$$
\begin{gathered}
{[\mathbf{F}]^{\mathrm{T}}\left[\mathbf{P}_{j}-\mathbf{B}\right]=0, j=1,2, \ldots, n} \\
{\left[\mathbf{W}_{j}\right]^{\mathrm{T}}\left[\mathbf{P}_{j}-\mathbf{B}\right]=0, j=1,2, \ldots, n}
\end{gathered}
$$

During the movement of the mechanism, the angle $\alpha$ between the input axis $F$ and the output axis $W$ also remains unchanged.

$$
\left[\mathbf{W}_{1}\right]^{\mathrm{T}}[\mathbf{F}]=\left[\mathbf{W}_{j}\right]^{\mathrm{T}}[\mathbf{F}], j=2,3, \ldots, n
$$

The stagger angle of the two axes may be $\alpha$ or $-\alpha$ to ensure the constant angle direction; thus, the constant moment constraint equation needs to be added.

$$
[\mathbf{F}]^{\mathrm{T}}\left[\left(\mathbf{P}_{1}-\mathbf{B}\right) \times \mathbf{F}_{1}\right]=[\mathbf{F}]^{\mathrm{T}}\left[\left(\mathbf{P}_{j}-\mathbf{B}\right) \times \mathbf{W}_{j}\right], j=2,3, \ldots, n
$$

The direction vectors of the input axis $F$ and the output axis $W$ should also satisfy the direction cosine equation.

$$
\begin{gathered}
{[\mathbf{F}]^{\mathrm{T}}[\mathbf{F}]=1} \\
{\left[\mathbf{W}_{1}\right]^{\mathrm{T}}\left[\mathbf{W}_{1}\right]=1}
\end{gathered}
$$

The constant moment equations (Equations (7)) contain Equations (3); hence, only Equations (7) need to be solved. The spatial 2R mechanism has 12 structural parameters: $\mathbf{F}=\left[f_{x}, f_{y}, f_{z}\right]^{\mathrm{T}}$, $\mathbf{B}=\left[\begin{array}{lll}b_{x} & b_{y}, & b_{z}\end{array}\right]^{\mathrm{T}}, \quad \mathbf{W}_{1}=\left[\begin{array}{lll}w_{x} & w_{y}, w_{z}\end{array}\right]^{\mathrm{T}}, \mathbf{P}_{1}=\left[\begin{array}{lll}p_{x} & p_{y}, & p_{z}\end{array}\right]^{\mathrm{T}}$. The simultaneous equations (Equations (4)-(9)) have a total of $4 j$ equations. To solve the mechanism parameters accurately, the number of equations must be less than or equal to the number of unknowns. Therefore, the spatial $2 \mathrm{R}$ mechanism can accurately achieve three given poses ${ }^{[21]}$. The spatial $2 \mathrm{R}$ mechanism that meets the design requirements can be obtained by establishing and solving the constraint equations.

\section{Transplanting mechanism design}

\subsection{Solution of transplanting mechanism parameters}

In accordance with the agronomic requirements of the WPST, the homogeneous matrices $\mathbf{T}_{1}, \mathbf{T}_{2}$, and $\mathbf{T}_{3}$ of the transplanting arm refer to that at the start of clamping (point 1), at the end of extracting (point 4), and at the start of pushing (point 8), respectively. Matrices $\mathbf{T}_{1}$ and $\mathbf{T}_{2}$ mainly constrain the posture

\begin{tabular}{|c|c|c|c|}
\hline \multirow{2}{*}{\multicolumn{2}{|c|}{ Unknowns }} & \multicolumn{2}{|c|}{ Solutions } \\
\hline & & 1 & 2 \\
\hline \multirow{3}{*}{$\mathbf{F}$} & $f_{x}$ & 0 & 0.2258 \\
\hline & $f_{y}$ & 0 & 0.1112 \\
\hline & $f_{z}$ & 1 & 0.9678 \\
\hline \multirow{3}{*}{ B } & $b_{x}$ & -0.0336 & -40.3790 \\
\hline & $b_{y}$ & -0.1504 & 81.8387 \\
\hline & $b_{z}$ & 366.5153 & 366.6734 \\
\hline \multirow{3}{*}{$\mathbf{W}_{1}$} & $w_{x}$ & 0.1314 & 0.2388 \\
\hline & $w_{y}$ & 0.0161 & 0.2403 \\
\hline & $w_{z}$ & 0.9912 & 0.9409 \\
\hline \multirow{3}{*}{$\mathbf{P}_{1}$} & $p_{x}$ & -5.9030 & -86.9044 \\
\hline & $p_{y}$ & 47.5839 & 88.6343 \\
\hline & $p_{z}$ & 366.5166 & 376.7452 \\
\hline
\end{tabular}
characteristics of the picking process, while $\mathbf{T}_{3}$ constrains the position and planting angle of the seedling pushing.

$\mathbf{T}_{1}=\left[\begin{array}{cccc}0.9777 & -0.1640 & 0.1312 & 244.1001 \\ 0.1633 & 0.9864 & 0.0162 & 130.5808 \\ -0.1321 & 0.0055 & 0.9912 & 856.4232 \\ 0 & 0 & 0 & 1\end{array}\right]$
$\mathbf{T}_{2}=\left[\begin{array}{cccc}0.8249 & -0.5565 & 0.0996 & 218.5180 \\ 0.5643 & 0.8210 & -0.0869 & 135.8228 \\ -0.0334 & 0.1279 & 0.9912 & 880.8332 \\ 0 & 0 & 0 & 1\end{array}\right]$
$\mathbf{T}_{3}=\left[\begin{array}{cccc}0.5725 & 0.8098 & -0.1283 & 67.7006 \\ -0.8138 & 0.5803 & 0.0320 & -162.0204 \\ 0.1003 & 0.0861 & 0.9912 & 904.8531 \\ 0 & 0 & 0 & 1\end{array}\right]$

The constraint equations of the spatial $2 \mathrm{R}$ mechanism are established on the basis of the method in the previous section. HOM4PS $2.0^{[22]}$, polyhedral homotopy continuation software, is used to solve the spatial $2 \mathrm{R}$ mechanism parameters, and two groups of real solutions are obtained, as shown in Table 1.

Table 1 Geometric parameters of spatial 2R mechanism

The first set of solutions is selected as the initial design parameters after considering the requirements of the planter mounting position and the size of the transplanting arm. From the parameters solved, the axis intersection angle $\alpha=7.6073^{\circ}$, the link length $L_{1}=48.0938 \mathrm{~mm}$, and $L_{2}=556.2360 \mathrm{~mm}$. However, using those parameters to design PGTM directly will result in the gear center distance being excessively small and the transplanting arm excessively long. To obtain a compact PGTM and reasonable planetary carrier (gear center distance) and transplanting arm length, a plane $N$ perpendicular to $F$-axis and within $\pm 50 \mathrm{~mm}$ from the clamping position $\mathbf{T}_{1}$ (to ensure the $z$-direction structure size of the transplanting arm) can be made. As shown in Figure 5, two intersection points $a$ and $b$ exist between plane $N$ and axes $F$ and $W$.

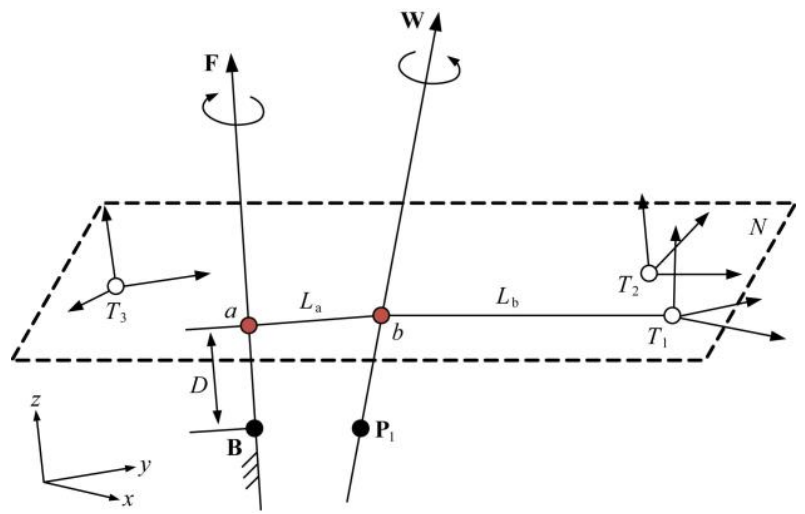

Figure 5 Determination of length parameters 
Line $L_{\mathrm{a}}$ between points $a$ and $b$ is the length of the planetary carrier, and line $L_{\mathrm{b}}$ between points $b$ and $\mathbf{T}_{1}$ is the length of the transplanting arm. On the basis of the design requirements of the height of the planet carrier of the transplanting mechanism from the ground, the distance between plane $N$ and point $\mathbf{B}$ is $493.4847 \mathrm{~mm}$. As a result, $L_{\mathrm{a}}=81.6 \mathrm{~mm}$ and $L_{\mathrm{b}}=188.3 \mathrm{~mm}$ can be obtained to generate a new spatial $2 \mathrm{R}$ mechanism. This mechanism is the same kinematic model as the solution model and has the same kinematic characteristics.

\subsection{Replaying and analyzing the trajectories of the transplanting mechanism}

In PGTM, planet carrier $L_{\mathrm{a}}$ rotates at a constant speed within $0-2 \pi$. As the transplanting arm $L_{\mathrm{b}}$ rotates at a variable speed relative to $L_{\mathrm{a}}$, the angular displacement of the planet carrier is set to $\theta_{1}$, and the angular displacement of the transplanting arm relative to the planetary carrier is $\theta_{2}$. The angular displacements of the planet carrier and the transplanting arm are divided using the solved mechanism parameters. The mechanism has three sets of relative angular displacements corresponding to the three spatial poses. One period of angular displacement is $2 \pi$, and a total of four groups of angular displacement exist. With $\theta_{1}$ as the abscissa and $\theta_{2}$ as the ordinate, the angular displacement relationship between $L_{\mathrm{a}}$ at a constant speed and $L_{\mathrm{b}}$ relative to $L_{\mathrm{a}}$ at variable speed can be established. The movement between the transplanting arm and the planetary carrier of PGTM cannot occur (the relative angular displacement within the period must be monotonic); therefore, nine data points are added in accordance with the linear law among the four sets of angular displacement data. The angular displacement curve through the 13 data points is interpolated with cubic nonuniform B-spline ${ }^{[23]}$. On the basis of the angular displacement curve, the kinematic replication of the spatial $2 \mathrm{R}$ mechanism can be performed to obtain the transplanting trajectory at the end of the mechanism. Combined with the trajectory requirements of WPST, the relative angular displacement curve is optimized by adjusting the added nine data points. The change in the trajectory is observed, and the influence of the data points on the shape of the transplanting trajectory is analyzed.

As shown in Figure 6, each data point on the displacement curve (Figure 6a) corresponds to each point on the trajectory curve (Figures 6b, 6c). Points 1, 4, and 8 on the displacement curve are the angular displacement relations corresponding to the given three points. Point 13 is the end point of one period and the start point of the next period, and the four points are fixed. The trajectory of picking and extracting seedlings in the transplanting trajectory is controlled using points 1-4 on the displacement curve. When the ordinate value of point 2 in Figure 6a changed from small to large, the beak-shaped trajectory of the extracting section of Figure $6 \mathrm{~b}$ changed. When the ordinate of point 2 on the displacement curve is relatively small, the trajectory of the beak-shaped section in Figure $6 \mathrm{~b}$ folds upward. The beak-shaped section gradually shifts to the lower right when the ordinate of point 2 gradually increases. At this time, the $z$-offset of the trajectory of the extracting section in Figure $6 \mathrm{c}$ gradually decreases. The success rate of seedling selection is reduced due to the excessive $z$-direction displacement of the seedling stage locus, and seedling paw tears out the pots and pushes down the adjacent seedlings during seedling extraction. Therefore, the effective length (greater than $20 \mathrm{~mm}$ ) and the smaller $z$-direction displacement of seedlings can be obtained by adjusting the angular displacement data point 2 .

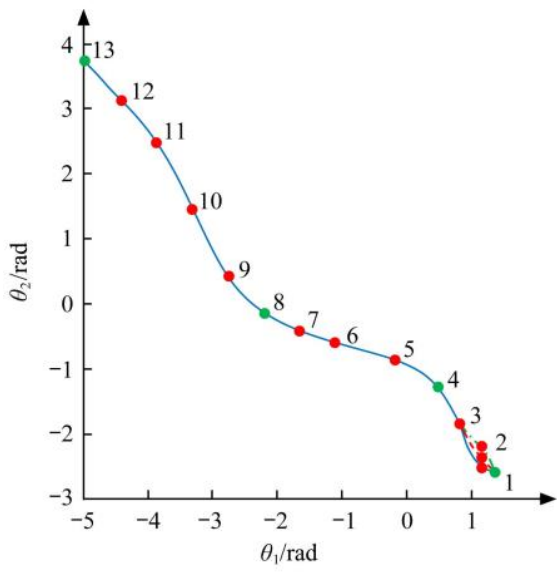

a. Angular displacement curve

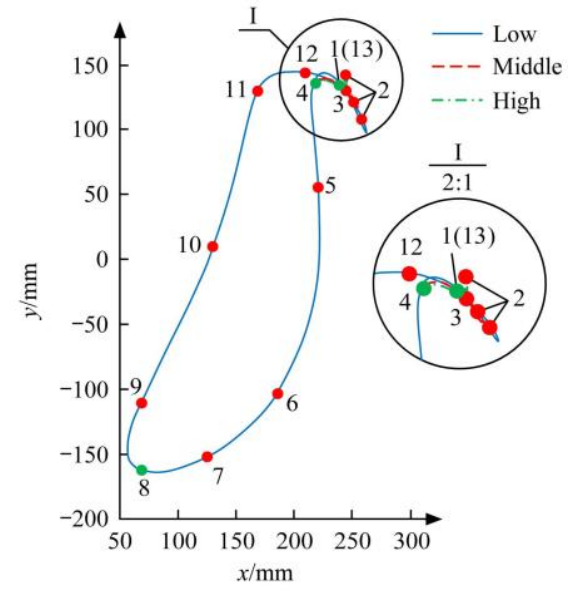

b. Trajectory curve $(x-y$ plane $)$

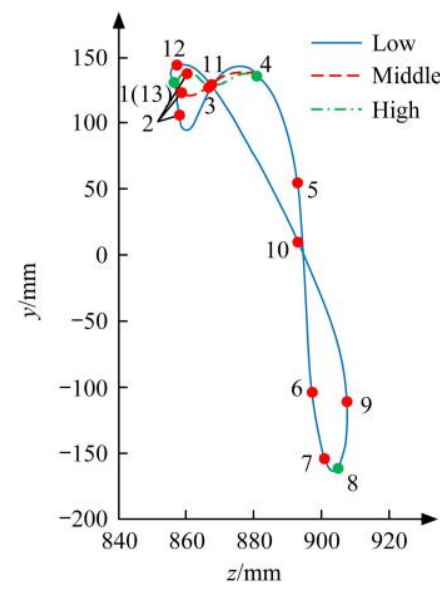

c. Trajectory curve ( $z-y$ plane)

Figure 6 Influence of the change in the ordinate of point 2 on the trajectory

Figure 7 depicts that the ordinate of point 5 on the angular displacement curve mainly affects the trajectory shape of the seedling-transporting process. When the ordinate value of point 5 on the angular displacement curve increases slightly, the trajectory in Figure $7 \mathrm{~b}$ gradually shifts to the left, causing a slight bulge of the trajectory in the seedling-extracting section. The corresponding point 5 on the trajectory in Figure $7 \mathrm{c}$ gradually moves to the right. If the trajectory of the seedling-transporting section is considerably convex to the right, the soil mass of the pot seedling is easy to collide with the seedling box and damage the nutrient soil bowl. Therefore, the effective distance between the trajectory and the seedling box can be controlled, and fine-tuning of the trajectory of extracting seedlings can be achieved by adjusting the ordinate of point 5 on the angular displacement curve.
In Figure $8 \mathrm{~b}$, point 8 on the trajectory curve is the point of completion of the seedling push, and the ordinate of point 9 on the displacement curve in Figure $8 \mathrm{a}$ is closely related to the shape of the trajectory after the seedling push. When the value of the ordinate of the angular displacement curve point 9 gradually decreases, the corresponding point 9 on the trajectory in Figure $8 b$ gradually moves to the left, leading to a gradual increase in the forward angle of this trajectory and an increase in the space distance at point 8 where the seedling is completed. In Figure 8c, the corresponding point 9 on the trajectory has no obvious change, indicating that it is inconsiderably related to the change in $z$ coordinate of the trajectory. The first half of the empty return trajectory (the trajectory between points 8 and 10 in Figure $8 b$ ) after the completion of the seedling push is excessively inclined. 
Consequently, the transplanting arm will easily push down the planted seedlings, and the seedlings will also be pushed down if they are considerably close to the seedling point. Under the premise that the shape of the non-circular gear pitch curve is reasonable, adjusting the ordinate of data point 9 on the angular displacement curve can solve the problem of the transplanting mechanism pushing down the seedlings.

As shown in Figure 9, the ordinate of point 11 on the angular displacement curve mainly affects the trajectory shape of the pre-seedling action segment. When the ordinate value of the angular displacement point 11 increases slightly, the corresponding point 11 on the trajectory in Figure 9b gradually moves upward, and the $z$-direction displacement between points 11 and 12 on the trajectory in Figure 9c gradually decreases. The success rate of seedling picking decreases due to the excessive $z$-direction displacement of the trajectory of the seedling picking preparation section. Therefore, the $z$-direction displacement of the trajectory of the seedling section can be reduced by adjusting point 11 on the angular displacement curve to improve the success rate of seedling picking of the transplanting mechanism.

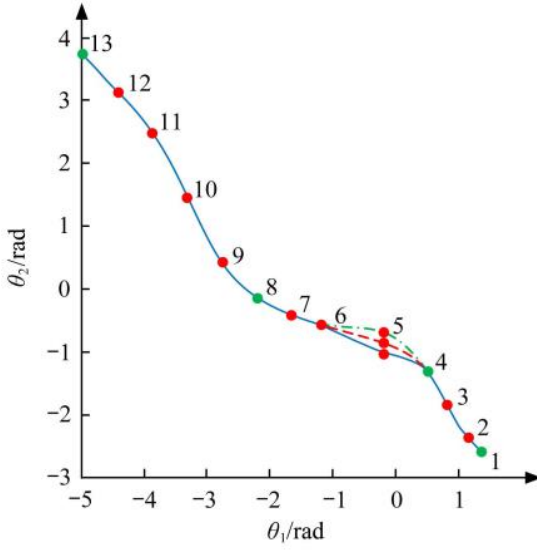

a. Angular displacement curve

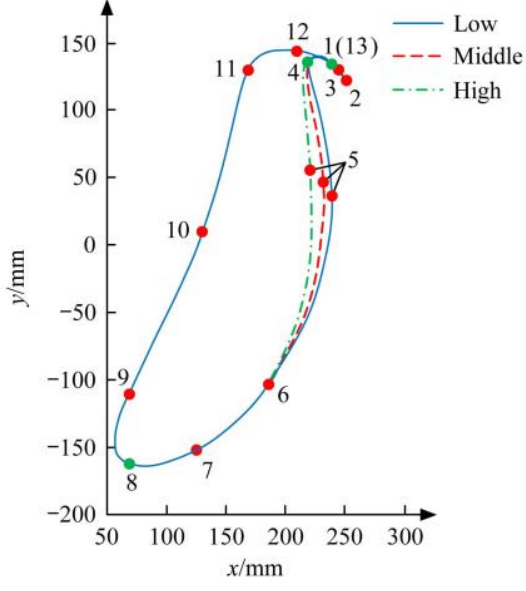

b. Trajectory curve ( $x-y$ plane)

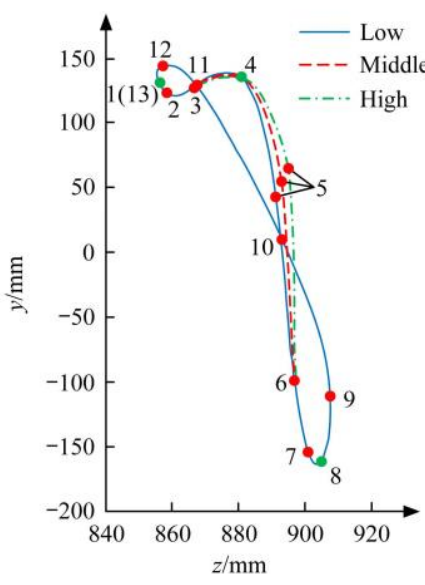

c. Trajectory curve (z-y plane)

Figure 7 Influence of the change in the ordinate of point 5 on the trajectory

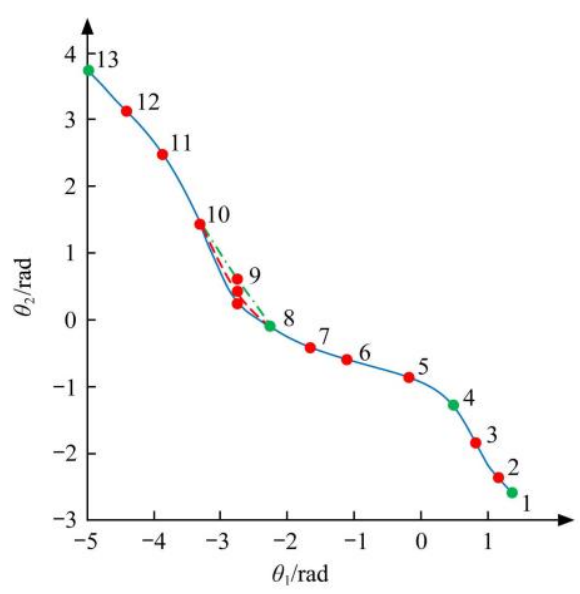

a. Angular displacement curve

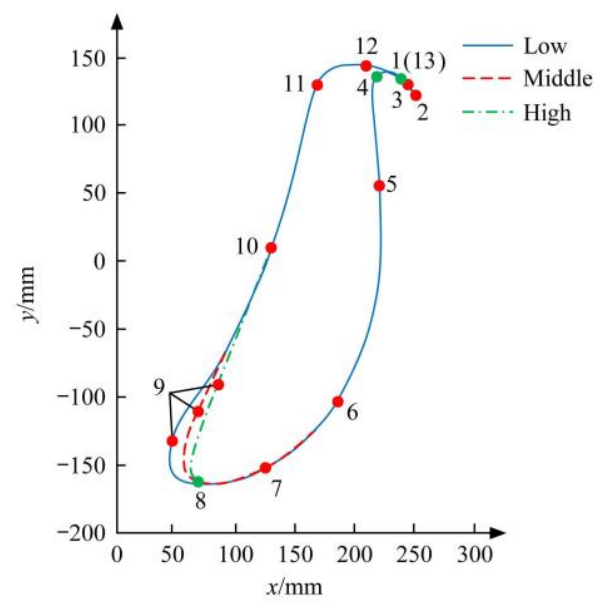

b. Trajectory curve ( $x-y$ plane)

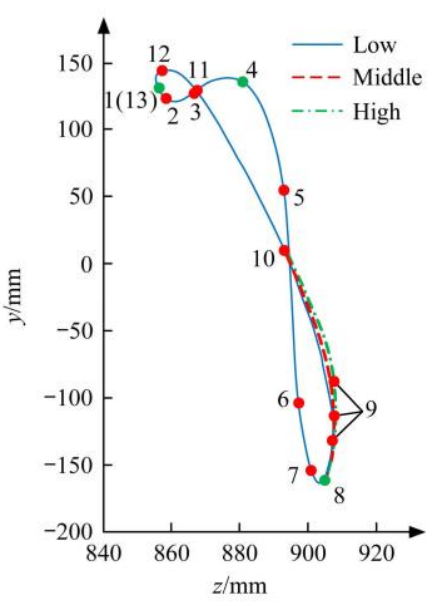

c. Trajectory curve ( $z-y$ plane)

Figure 8 Influence of the change in the ordinate of point 9 on the trajectory

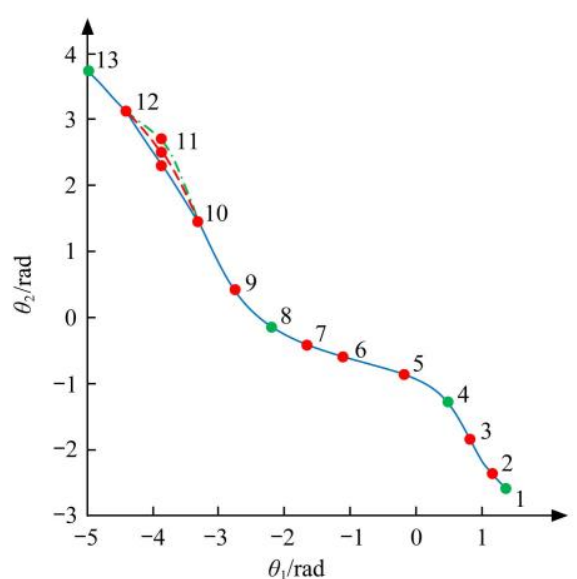

a. Angular displacement curve

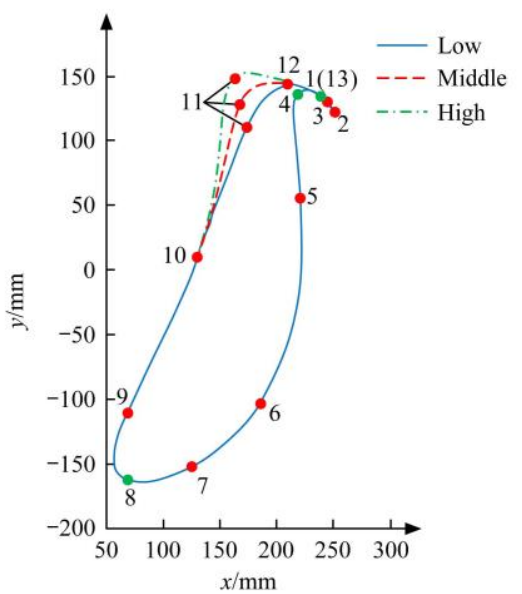

b. Trajectory curve ( $x-y$ plane $)$

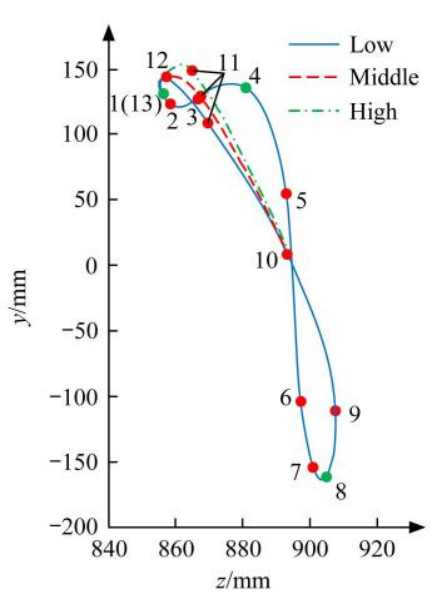

c. Trajectory curve $(z-y$ plane $)$

Figure 9 Influence of the change in the ordinate of point 11 on the trajectory 
Combined with the trajectory requirements of WPST and the monotonicity of the angular displacement of the transplanting arm $\left(L_{\mathrm{b}}\right)$ relative to the planet carrier $\left(L_{\mathrm{a}}\right)$, the optimized relative angular displacement curve and transplanting trajectory are obtained by adjusting the variable parameters of nine data points on the angular displacement curve, as shown in Figure 10. In accordance with the conversion relationship between the $2 \mathrm{R}$ mechanism and PGTM, the reciprocal of the slope value of the relative angular displacement curve is the value of the total transmission ratio of PGTM ${ }^{[24]}$; the total transmission ratio curve can be solved, as shown in Figure 11.
After the transmission ratio curve of the mechanism is obtained, various PGTMs that can realize spatial trajectory can be acquired by attaching different non-circular gear pairs to reduce the degree of freedom of the $2 \mathrm{R}$ mechanism ${ }^{[19]}$. In this study, the combined transmission of planar non-circular and non-conical gears is adopted. On the basis of the distribution principle of two-stage transmission gear ratio ${ }^{[25]}$, the total transmission ratio is divided into two sub-transmission ratios (Figure 11), and the pitch curve and tooth profile of the non-circular gear are calculated, as shown in Figure 12.

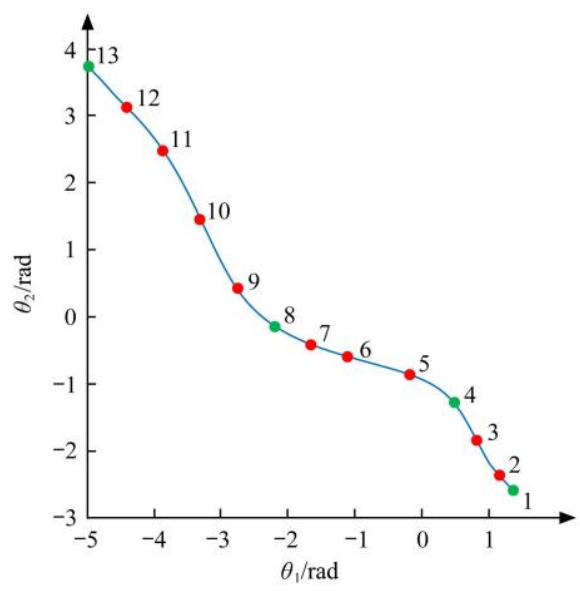

a. Angular displacement curve

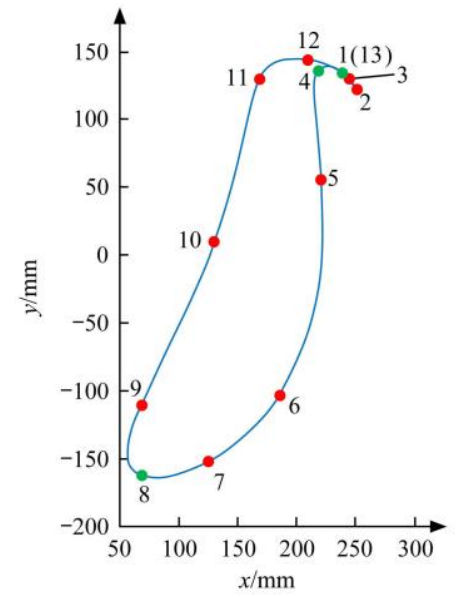

b. Trajectory curve ( $x-y$ plane)

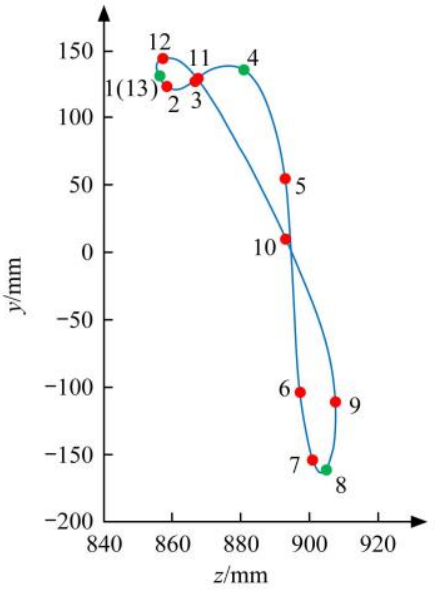

c. Trajectory curve $(z-y$ plane)

Figure 10 Optimized relative angular displacement curve and trajectory

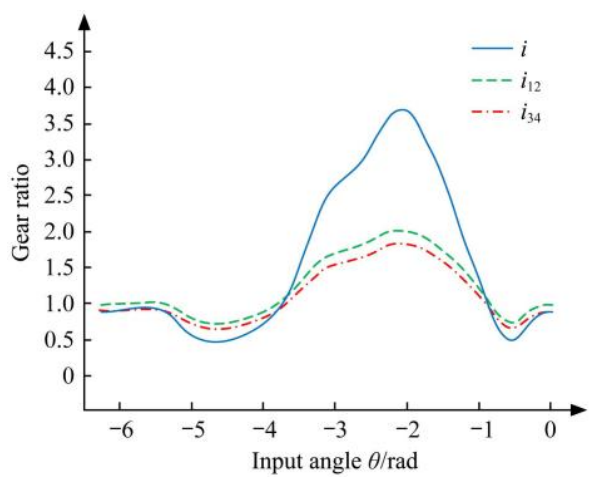

Figure 11 Transmission ratio curve
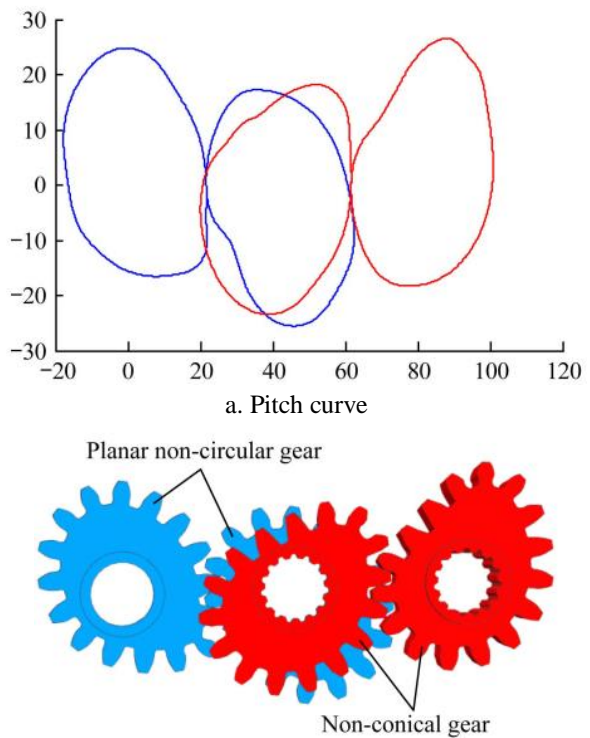

b. Tooth profile

Figure 12 Combined transmission of planar non-circular and non-conical gears

\section{Simulation and test of transplanting mechanism}

\subsection{Trajectory verification}

The structure design and 3D modeling of a clamping-pot-type PGTM for rice WPST were conducted in accordance with the structure parameters of the mechanism and the optimized non-circular gear. The simulation test of the virtual prototype was completed on Adams software, and the trajectory of the tip of the transplanting arm was obtained, as shown in Figure 13. The physical prototype of the transplanting mechanism was processed, and the idling test was performed. The high-speed camera technology is used to capture video images from the front and side of the transplanting mechanism. Then, the image analysis software Blaster's MAS is used to analyze the test video to obtain the actual motion trajectory, as shown in Figure 14. The comparison indicated that the tested and simulated trajectories of the transplanting mechanism were basically consistent with the ideal trajectory. In addition, in the software Blaster's MAS, the lateral offset of the mechanism from the starting point of clamping seedlings to the point of pushing seedlings is measured as $46.17 \mathrm{~mm}$

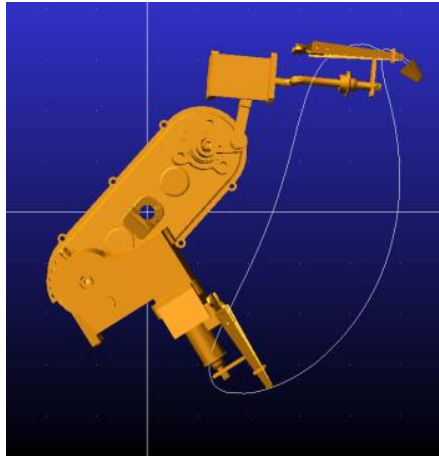

a. $x$-y plane

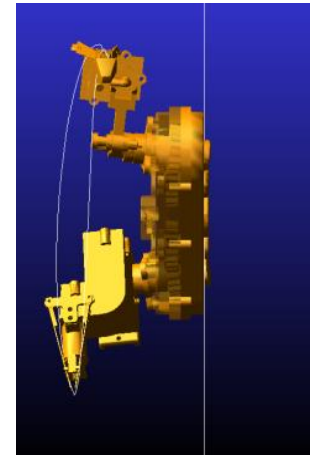

b. $z-y$ plane
Figure 13 Simulated trajectory 
(Figure 14b), indicating that the clamping-pot-type PGTM can realize WPST (wide-row distance $392.34 \mathrm{~mm}$ and narrow-row distance $207.66 \mathrm{~mm}$ ). The correctness of the design of the transplanting mechanism was initially verified.

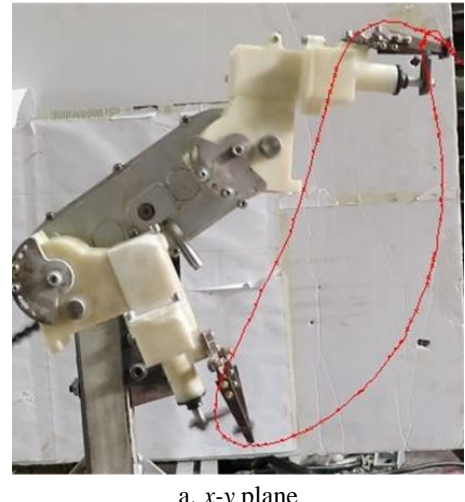

Figure 14 Tested trajectory

On the premise of the reasonable verification of the transplanting trajectory, the posture of the transplanting arm at the three key poses of the clamping-pot-type PGTM for rice WPST was also verified. The transplanting arm postures of the

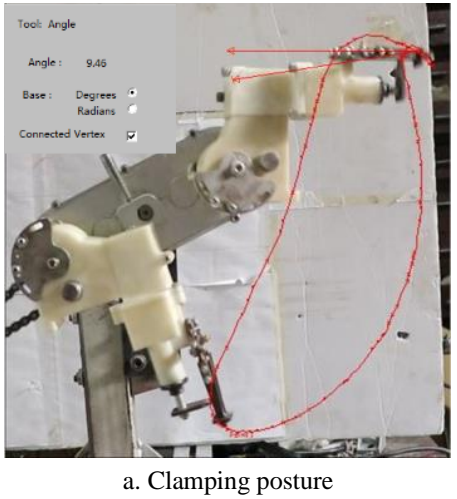

\subsection{Picking seedling test}

The physical prototype of the transplanting mechanism was installed on the rice pot seedling test bench (Figure 16) to conduct the seedling test and evaluate the transplanting performance of the transplanting mechanism in actual work. A pot tray with 406 holes ( 14 columns $\times 29$ rows) was used for the test, and the seedling age of rice seedlings is approximate $35 \mathrm{~d}$, and the seedling height is about $140 \mathrm{~mm}$.

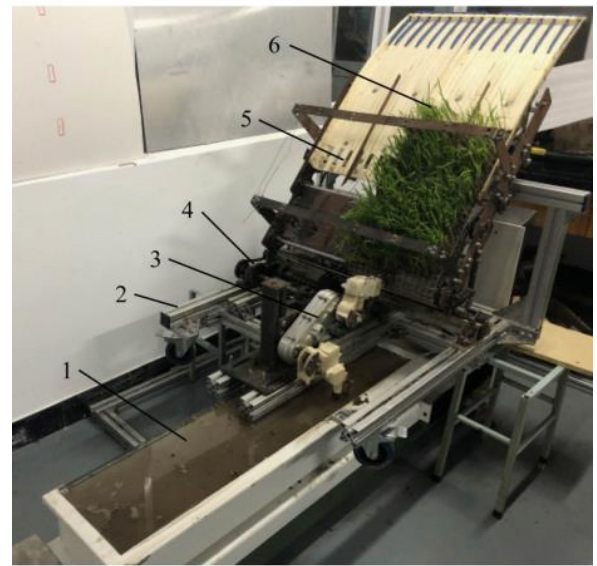

1. Soil bin 2. Rock 3. Transplanting mechanism 4. Power transmission mechanism 5. Seedling box 6. Pot seedlings

Figure 16 Test bench

b. Extracting posture

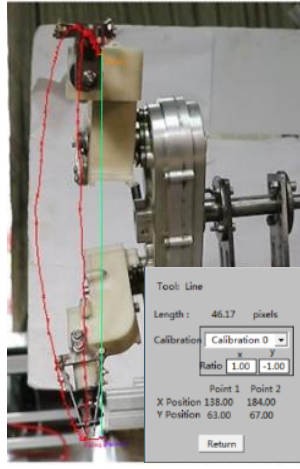

transplanting mechanism at the three positions of seedling clamping, extracting, and pushing are shown in Figure 15. The design angle of the transplanting arm structure was $15^{\circ}$. In the image analysis software Blaster's MAS, the posture angles of the mechanism at the three key poses were measured and compared with the theoretical value. The results are shown in Table 2.

Table 2 Posture verification results

\begin{tabular}{lccc}
\hline \multicolumn{1}{c}{ Posture angle } & Theoretical value & Measured value & Error \\
\hline Clamping angle $\alpha_{1} /\left(^{\circ}\right)$ & 9.44 & 9.46 & 0.02 \\
Extracting angle $\alpha_{2} /\left(^{\circ}\right)$ & 19.13 & 18.07 & -1.06 \\
Pushing angle $\alpha_{3} /\left(^{\circ}\right)$ & 69.37 & 69.49 & -0.12 \\
Lateral angle of pushing $\beta /\left(^{\circ}\right)$ & 4.94 & 5.49 & 0.45 \\
\hline
\end{tabular}

From the measurement results, the measured values of the transplanting mechanism were basically consistent with the theoretical values. Some deviations were due to the influences of machining accuracy, non-circular gear clearance, measurement accuracy, and other factors, and the deviations were all within a reasonable range. These conditions met the agronomic requirements of rice transplanting in wide and narrow rows and verified the feasibility and rationality of the transplanting mechanism design.

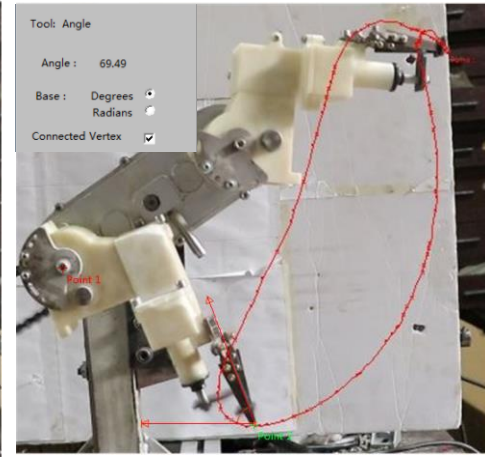

c. Pushing posture $(x-y$ plane $)$

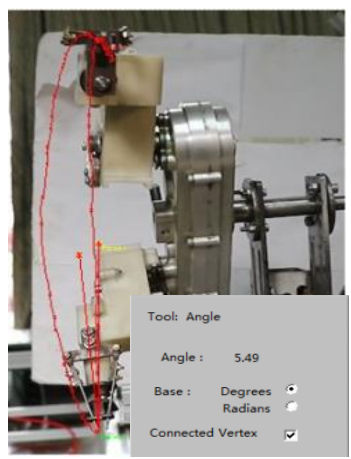

d. Pushing posture ( $z-y$ plane)
Figure 15 Transplanting arm posture verification

The operating rotational speed of the transplanting mechanism was set to 50 and $90 \mathrm{r} / \mathrm{min}$. A total of 406 seedlings were collected each time. The operation process of the transplanting mechanism was photographed with a camera, and the working posture of the transplanting mechanism was observed. The number of seedlings collected was recorded, and the success rate of seedlings collected was analyzed. Figures $17 \mathrm{a}, 17 \mathrm{~b}, 17 \mathrm{c}$ show the positions and postures of the transplanting arm during seedling clamping, extracting, and pushing, respectively. The transplanting effect of the mechanism is shown in Figure 17d. The results of the picking seedling test are shown in Table 3 .

Table 3 Results of picking seedling test

\begin{tabular}{cccc}
\hline $\begin{array}{c}\text { Rotational } \\
\text { speed/r } \cdot \text { min }^{-1}\end{array}$ & $\begin{array}{c}\text { Number of seedlings } \\
\text { (plant) }\end{array}$ & $\begin{array}{c}\text { Seedlings picked } \\
\text { (plant) }\end{array}$ & $\begin{array}{c}\text { Success rate of } \\
\text { picking/\% }\end{array}$ \\
\hline 50 & 406 & 387 & 95.32 \\
90 & 406 & 366 & 90.15 \\
\hline
\end{tabular}

The picking seedling test showed that the transplanting mechanism could successfully clamp and push the seedlings. When the rotational speed is $50 \mathrm{r} / \mathrm{min}$ (the seedling picking efficiency is 100 plants per minute per row), the success rate of seedling picking is $95.32 \%$, which is higher than the success rate of seedling picking of the clamping-pot-type transplanting mechanism $(93.06 \%)$ in literature [12]. Furthermore, the average success rate of seedling picking of the clamping-pot-type rice transplanting 
mechanism in reference [12] was $88.89 \%$ when the rotation speed was $80 \mathrm{r} / \mathrm{min}$. In the study, the success rate of seedling picking is $90.15 \%$ when the mechanism rotation speed is $90 \mathrm{r} / \mathrm{min}$, which is also higher than that of the previous clamping-pot-type transplanting mechanism ${ }^{[12]}$. Additionally, compared with the clamping-seedling-type transplanting mechanism of rice WPST in references [11] and [19], the seedlings planted by the clamping-pot-type PGTM for rice WPST has superior uprightness, which reflects the advantages of picking seedlings by

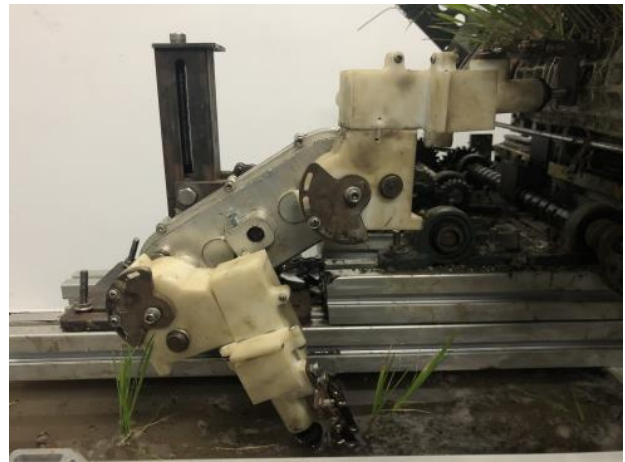

a. Clamping position

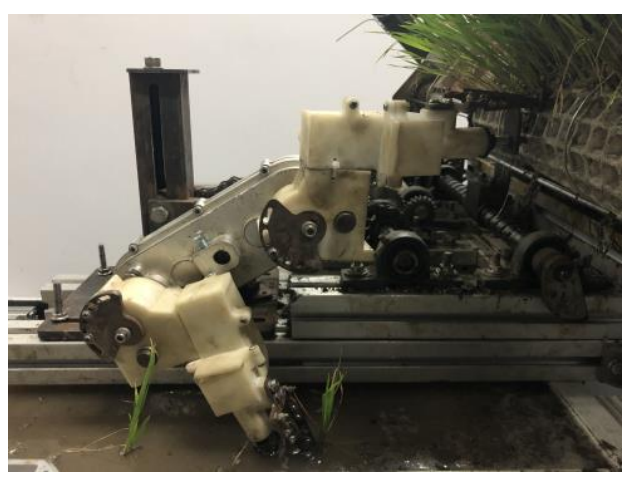

c. Pushing position clamping soil pots.

The clamping-pot-type PGTM for rice WPST designed in this work has a high success rate of picking seedlings and planting uprightness, which can be applied to rice pot seedling transplanters. However, the success rate of seedling picking at high rotation speed still needs to be improved. In the future, experimental research on the specific transplanting effect of the mechanism should be conducted, and the mechanism should be improved to achieve the best performance.

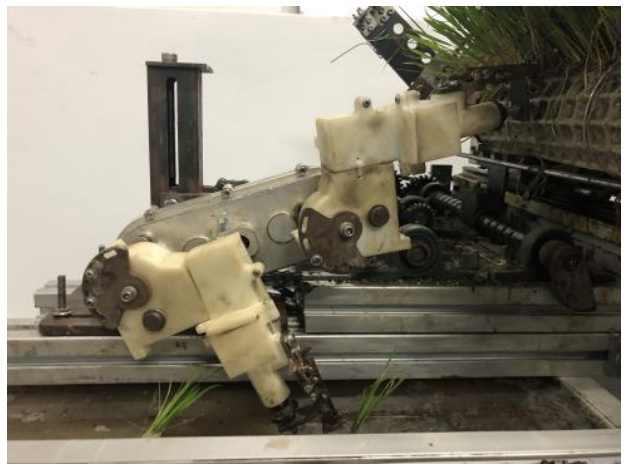

b. Extracting position

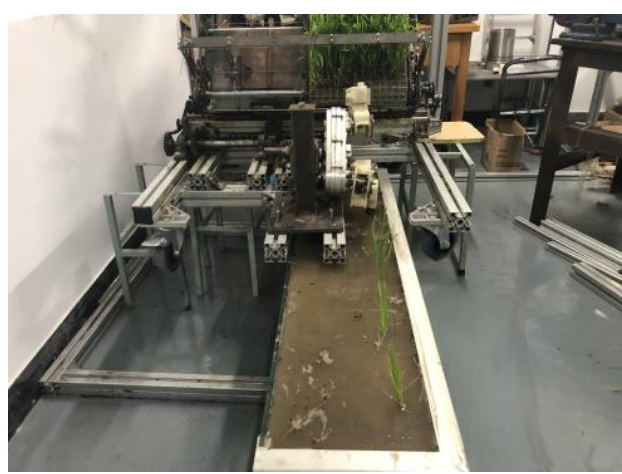

d. Transplanting effect

Figure 17 Picking seedling test

\section{Conclusions}

1) A new design method of a spatial PGTM based on several spatial poses was proposed. The geometric constraint equations of the spatial motion of the spatial $2 \mathrm{R}$ mechanism were established, and all geometric parameters of the mechanism were obtained using a polyhedral homotopy algorithm.

2) The relative angular displacement curve among the links of the spatial $2 \mathrm{R}$ mechanism was optimized, and the total transmission ratio of the mechanism was determined. The conversion between the linkage mechanism and PGTM was realized by attaching the nonequal-speed gear pair to the spatial 2R mechanism.

3) A spatial clamping-pot-type PGTM for rice WPST driven by the combination of planar non-circular and non-conical gears was designed. The virtual simulation and prototype test were conducted. The results showed that the actual and simulation trajectories and postures were basically consistent with the given ideal trajectory and posture, which verified the feasibility of the theoretical method. At the operating speeds of $50 \mathrm{r} / \mathrm{min}$ and $90 \mathrm{r} / \mathrm{min}$, the success rates of seedling picking were $95.32 \%$ and $90.15 \%$, respectively, which basically met the requirements of pot seedling transplantation.

This study could provide a reference for the design of a spatial PGTM with nonuniform transmission. In the future, the specific transplanting effect and quality of the transplanting mechanism will be further studied and improved to make the mechanism achieve the best performance.

\section{Acknowledgements}

This work was supported by the National Key Research and Development Program of China (Grant No. 2018YFD0700703), the National Natural Science Foundation of China (Grant No. 51975534, 51675487), the Zhejiang Provincial Key Research and Development Program (Grant No. 2018C02046), the Natural Science Foundation of Zhejiang Province (Grant No. LY19E050021), the 151 Talent Plan of Zhejiang Province, and the Project of Zhejiang Provincial Young and Middle-aged Discipline Leaders.

\section{[References]}

[1] Tong S Y, Du Z Y. Effects of wide-narrow row spacing cultivation on growth and yield of rice. Heilongjiang Agricultural Sciences, 2011; 3: 30-32. (in Chinese)

[2] Gao F Q, Zhang S Q. Research and popularization of wide and narrow row spacing cultivation techniques for rice. China Rice, 2018; 24(4): 22-23, 26. (in Chinese)

[3] Zhang Y S. Optimization design and test of transplanting mechanism based on clipping rice plug-seeding. Master dissertation. Hangzhou: Zhejiang Sci-Tech University, 2018; 67p. (in Chinese)

[4] Yu X X, Zhao Y, Chen B C, Zhou M L, Zhang H, Zhang Z C. Current situation and prospect of transplanter. Transactions of the CSAM, 2014; 45(8): 44-53. (in Chinese)

[5] Xu C L, Lü Z J, Xin L, Zhao Y. Optimization design and experiment of 
full-automatic strawberry potted seedling transplanting mechanism. Transactions of the CSAM, 2019; 50(8): 97-106. (in Chinese)

[6] Yu G H, Tong Z P, Sun L, Tong J H, Zhao X. Novel Gear Transmission mechanism with twice unequal amplitude transmission ratio. Journal of Mechanical Design, 2019; 141(9): 1-23.

[7] Konishi T, Horio M, Yoshida S. Development of high performance rice transplanter. Transactions of the JSAM, 1989; 51(5): 89-95

[8] Zhou M L, Sun L, Du X Q, Zhao Y, Xin L. Optimal design and experiment of rice pot seedling transplanting mechanism with planetary Bezier gears. Transactions of the ASABE, 2016; 57(6): 1537-1548.

[9] Ye B L, Jin X J, Yu G H, Li L, Gao Y, Zhu H. Parameter modification guiding optimization design and tests of a rotary transplanting mechanism for rice plug seedlings. Applied Engineering in Agriculture, 2015; 31(6): 863-873.

[10] Ye B L, Yi W M, Yu G H, Gao Y, Zhao X. Optimization design and test of rice plug seedling transplanting mechanism of planetary gear train with incomplete eccentric circular gear and non-circular gears. Int J Agric \& Biol Eng, 2017; 10(6): 43-55.

[11] Sun L, Mao S M, Zhao Y, Liu X L, Zhang G F, Du X Q. Kinematic analysis of rotary transplanting mechanism for wide-narrow row pot seedlings. Transactions of the ASABE, 2016; 59(2): 475-485.

[12] Yu G H, Jin Y, Chang S S, Ye B L, Gu J B, Zhao X. Design and test of clipping-plug type transplanting mechanism of rice plug-seedling. Transactions of the CSAM, 2019; 50(7): 100-108. (in Chinese)

[13] Guo L S, Zhang W J. Kinematic analysis of a rice transplanting mechanism with eccentric planetary gear trains. Mechanism and Machine Theory, 2001; 36(11): 1175-1188.

[14] Bae K Y. Design of a rice transplanting mechanism with noncircular planetary-gear-train system. Journal of the Korean Society for Precision Engineering, 2005; 22(12): 108-116. (in Korean)

[15] Zhao X, Wang C, Yang M X, Sun L, Chen J N. Reverse design and analysis of automatic seedling pick-up mechanism with non-circular gear planetary train. Transactions of the CSAE, 2015; 31(16): 30-36. (in Chinese)
[16] Sun L, Zhu J B, Chen J N, Zhao Y, Wu C Y. Reverse design of transplanting mechanism with spatial planetary gear train based on spherical curve. Transactions of the CSAE, 2014; 30(7): 9-17. (in Chinese)

[17] Sun L, Xin Z Q, Xu Y D, Liu B, Yu G H, Wu C Y. Transplanting mechanism of rice seedling based on precise multi-position analysis. Transactions of the CSAM, 2019; 50(9): 78-86. (in Chinese)

[18] Sun L, Wang Z F, Wu C Y, Zhang G F. Novel approach for planetary gear train dimensional synthesis through kinematic mapping. Proceedings of the Institution of Mechanical Engineers, Part C: Journal of Mechanical Engineering Science, 2020; 234(1): 273-288.

[19] Sun L, Zhou Y Z, Huang H M, Wu C Y, Zhang G F. Analysis and design of a spatial planetary noncircular gear train for rice seedling transplanting based on three given positions. Transactions of the ASABE, 2020; 63(1): 165-176.

[20] Perez A, Mccarthy J M. Dimensional synthesis of Bennett linkages Journal of Mechanical Design, 2003; 125(1): 98-104.

[21] Mavroidis C, Lee E, Alam M. A new polynomial solution to the geometric design problem of spatial R-R robot manipulators using the denavit and Hartenberg parameters. Journal of Mechanical Design, 2001; 123(1): 58-67.

[22] Lee T L, Li T Y, Tsai C H. HOM4PS-2.0: a software package for solving polynomial systems by the polyhedral homotopy continuation method. Computing, 2008; 83(2): 109-133.

[23] Kano H, Egerstedt M, Nakata H, Martin C F. B-splines and control theory. Applied Mathematics and Computation, 2003; 145(2): 263-288.

[24] Ye J, Zhao X, Wang Y, Sun X C, Chen J N, Xia X D. A novel planar motion generation method based on the synthesis of planetary gear train with noncircular gears. Journal of Mechanical Science and Technology, 2019; 33(10): 4939-4949.

[25] Zhao X. Optimal design and experiment research of planetary gear train with two-order non-circular gears seedling pick-up mechanism on seedling transplanter. Doctoral dissertation. Hangzhou: Zhejiang Sci-Tech University, 2014; 124p. (in Chinese) 